MATEC Web of Conferences 48,02001 (2016)

DOI: $10.1051 /$ matecconf $/ 20164802001$

(C) Owned by the authors, published by EDP Sciences, 2016

\title{
Stiffness estimation for large-sized umbrella space reflector
}

\author{
Alexey Belkov ${ }^{1}$, Sergey Belov ${ }^{1, a}$, Mikhail Pavlov ${ }^{1}$, Victor Ponomarev $^{1}$, Sergey Ponomarev ${ }^{1}$ and Andrey \\ Zhukov $^{1}$ \\ ${ }^{1}$ National Research Tomsk State University, 634050 Tomsk, Russia
}

\begin{abstract}
This work describes stiffness estimation for new large-sized (with aperture more than $50 \mathrm{~m}$ ) umbrella space reflector. Reflector stiffness is measured by natural frequencies. Mode shapes and respectively natural frequencies are calculated by finite element method. First four natural frequencies with respectively mode shapes are presented.
\end{abstract}

\section{Introduction}

Currently, large-sized deployable space reflectors (antennas) are widely used due to their effective deployment within significant coverage per relatively small mass. Such antennas are usually classified as hoop («AstroMesh») and umbrella («Halca», «Garuda-1») type [1,2].

One of the major requirements for the space reflector frame is stiffness level i.e. the mechanical design property to resist external factors. However, there exists inconsistency between required high stiffness and increasing geometrical coverage of space reflectors to space payload weight, which in its turn, would influence the missile vehicle launching in to space orbit. To retain weight limitation under conditions of increasing reflector sizes, it is essential to decrease cross section area of frame elements which results in lower frame stiffness. In this case numerical stiffness analysis is an important phase in designing these systems.

\section{Natural frequency spectra characterizing stiffness of mechanical systems}

As a result of external loads the mechanical systems deforms - the more the stiffness, the less the deformation.

Large-sized space reflector is tensioned cable-stayed structures with thin tensile metallic mesh, forming the reflective surface. Such mechanical systems should satisfy the requirements affecting the mechanical behavior itself. In particular, reflector should retain its optimal reflector surface shape under specific operation loads, while root mean square (RMS) error of reflecting surface should not be more than $2-3 \%$ of the operating wavelength.

To estimate space reflector stiffness level, the spectrum of natural frequencies is applied. Natural frequency values in estimating stiffness can be shown in terms of one - dimensional mechanical system with focused parameters, which, in its turn, demonstrates finite stiffness [3].

\footnotetext{
${ }^{a}$ Corresponding author : belovsv@niipmm.tsu.ru

This is an Open Access article distributed under the terms of the Creative Commons Attribution License 4.0, which permits unrestricted use, distribution, and reproduction in any medium, provided the original work is properly cited.
} 


\section{MATEC Web of Conferences}

In [3] expression for mechanical system amplitude is presented as a function $A=A\left(f, m, \omega, \omega_{0}\right)$ :

$$
A=\frac{f}{m} \cdot \frac{1}{\sqrt{\left(\omega_{0}^{2}-\omega^{2}\right)^{2}}},
$$

where, $f$-external force amplitude, $m$ - mass, $\omega$-external force frequency, $\omega_{0}$ - natural frequency.

The most preferable case is $\omega_{0} \gg \omega$. In this case the mechanical system relative to external dynamic load would behave as a rigid body. In the above formula it is important that dynamic stiffness depends on natural frequency and external force amplitude.

The most negative case is when $\omega_{0}=\omega$, where the mechanical system experiences a resonance. This resonance causes $A \rightarrow \infty$. For real systems amplitude is damped either by properties of materials, joint defects and special damper or they are destroyed.

In static case, when $\omega \rightarrow 0$,

$$
A=\frac{f}{m} \cdot \frac{1}{\omega_{0}^{2}}
$$

there is a static deflection. In this case this value indicates stiffness and has the following dimension $\mathrm{N} / \mathrm{m}$. Thus, the parameter $\omega_{0}$ characterizes stiffness of the mechanical system - the higher the natural frequency, the less the static deflection.

As the beam elements, forming the framework, are of significant length, beam stiffness is either comparable to or less stiff than the joints. Consequently, the reflector is a mechanical system with parameter distribution. To determinate the stiffness of such structure, finite element method is applied to calculate natural frequencies, as the analytical approach is entirely unsuited for this. This can be explained by the fact analytical approach is suited for problems with small dimension.

To define the natural frequencies of the reflector it is necessary to know the stress and strain state of the reflector itself. Thus, determining the natural frequencies of the reflector involves two stages:

- stress and strain state definition for min. RMS error for reflector surface;

- natural frequencies definition at stress and strain state of the reflector.

The first stage is described in [4], therefore, only the second stage is described in details.

\section{Modal analysis}

In finite element discretization, motion equations for elementary dampingless volume with free oscillations are:

$$
\mathbf{M u ̈}+\mathbf{K u}=\mathbf{0},
$$

where $\mathbf{M}$ - mass matrix, $\mathbf{u}$ - displacement vector for each element node, $\mathbf{K}-$ stiffness matrix for all structure elements.

Equation (3) solution is:

$$
\mathbf{u}=\boldsymbol{\varphi} \cdot \cos \omega t
$$

where, $\boldsymbol{\varphi}$ - vector of mode shapes, $\omega$ - circular frequency.

Subtituting (4) into (3), we obtain the equation (5) :

$$
\left(\mathbf{K}-\omega^{2} \mathbf{M}\right) \boldsymbol{\varphi}=0 .
$$

The circular frequencies $\omega$ are obtained by the equation (6): 


$$
\left|\mathbf{K}-\omega^{2} \mathbf{M}\right|=0 .
$$

Vectors $\boldsymbol{\varphi}_{i}$ which correspond to circular frequencies $\omega_{i}$ are obtained by equation (7):

$$
\left(\mathbf{K}-\omega_{i}^{2} \mathbf{M}\right) \boldsymbol{\varphi}_{i}=0
$$

where $i=\overline{1, N}_{D O F}, N_{D O F}$ - number degree of freedoms.

This is eigenvalue problem. It is solved by Block Lanczos method [5]. Natural frequencies can be expressd by circular frequences:

$$
f_{i}=\omega_{i} / 2 \pi
$$

Expression (8) we use for stiffness estimation of umbrella reflector.

\section{Umbrella reflector description}

Figure 1 shows finite element models of the umbrella type reflector in sections and assembled section.

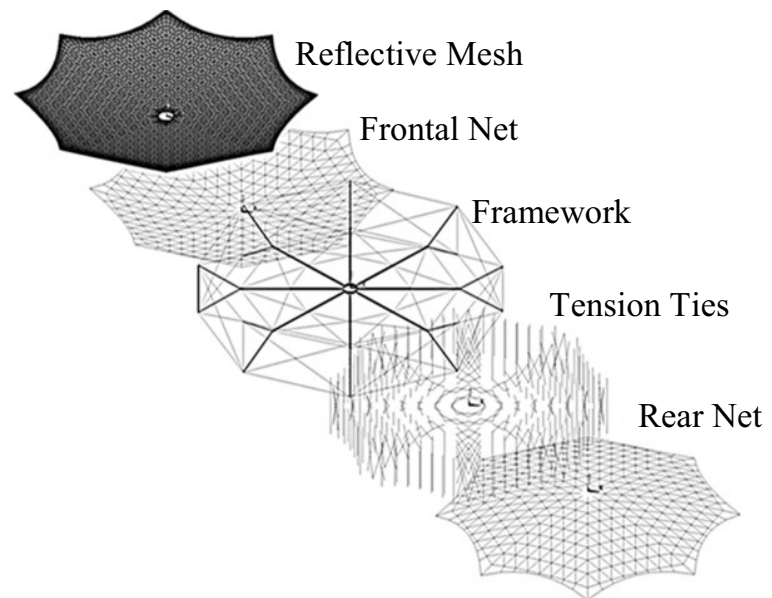

a)

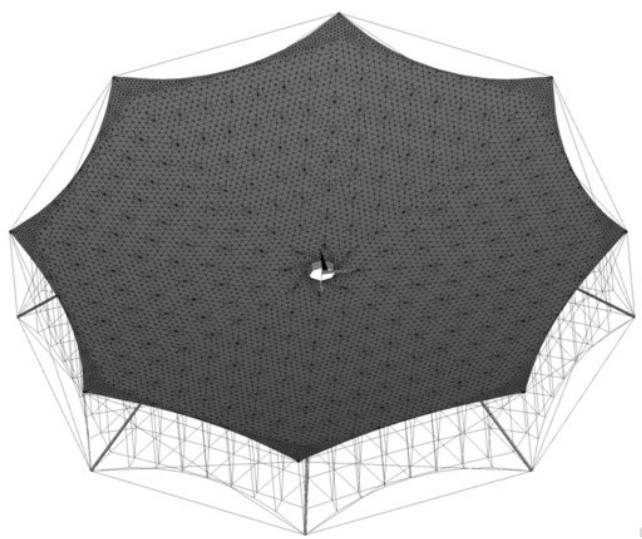

b)

Figure 1. Umbrella reflector: a) Reflector sections; b) Assembled reflector.

One can see that the reflector consists of reflective mesh which is modeled as a membrane without flexural stiffness, frontal net, rear net, tension ties which are modeled as cords with constant cross section area, which are subjected to tension. Framework is modeled of telescopic spokes which consist of grid-type beam elements the length of which can be seen in Figure 2. All spokes are gathered at central hub which is modeled by shell and beam elements. 


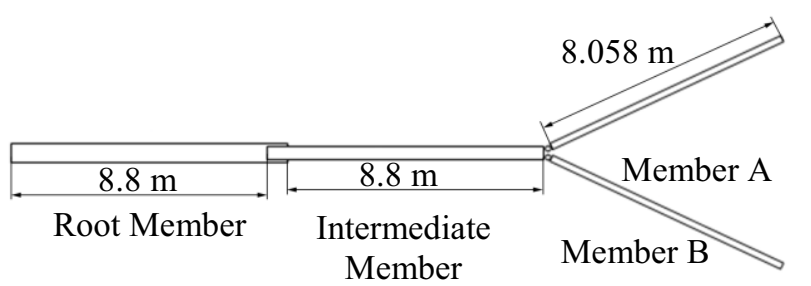

Root Member

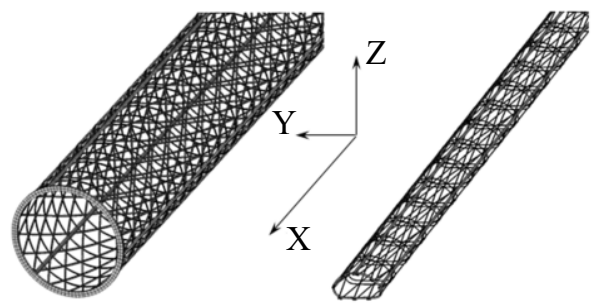

Member A

Figure 2. Grid-type telescopic spokes.

Diameters of the root and intermediate members are of $0.308 \mathrm{~m}$ and $0.256 \mathrm{~m}$, respectively. For A and $\mathrm{B}$ members are max of $0.18 \mathrm{~m}$ and $\min 0.095 \mathrm{~m}$ diameters.

\subsection{Reflective surface geometry description}

Reflective surface consists of frontal net and reflective mesh. It's geometry (so-called offset paraboloid) is the intersection of revolution paraboloid with focal distance $-32 \mathrm{~m}$ and cylinder of diameter $40 \mathrm{~m}$. Cylinder and paraboloid axes are parallel and separated by a clearance of $8 \mathrm{~m}$ (figure 3 a). Figure 3 b) shows topology of the frontal net.

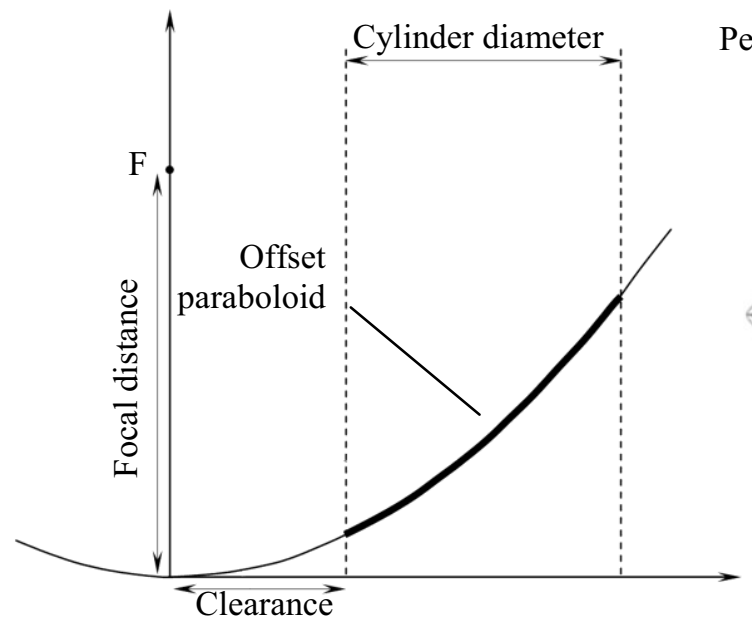

a)

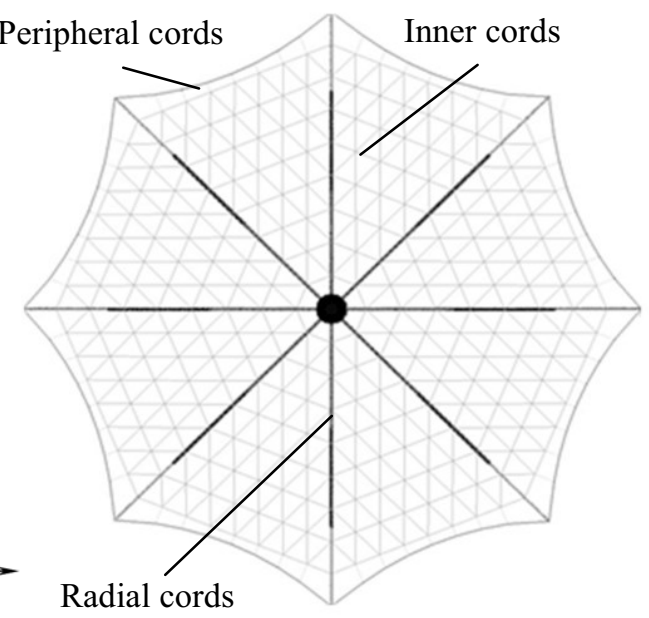

b)

Figure 3. Reflecting surface geometry: a) Offset reflector parameters b) Frontal net topology.

Plane geometry of peripheral cords are defined by the parabola in the equation $y(x)=\left(4 D / L^{2}\right) x^{2}-D$, where $L$ - distance between ends of A members of neighboring spokes, $D>0$ defines sag of the parabola.

Inner cords have diameter of $0.7 \mathrm{~mm}$, tension ties of $0.4 \mathrm{~mm}$. All other cords have a diameter of $2 \mathrm{~mm}$. Reflective mesh has a thickness of $0.1 \mathrm{~mm}$. 


\subsection{Mechanical characteristics and properties of materials}

Table 1 defines mechanical characteristics of spokes and their joints. It includes bending stiffness of all spoke members, member joint torsion stiffness. Table 2 defines properties of cord materials.

Table 1. Mechanical characteristics.

\begin{tabular}{|c|c|c|}
\hline Member & \multicolumn{2}{|c|}{ Bending stiffness, $\mathbf{N} \cdot \mathbf{m}^{2}$} \\
\hline Root Members & \multicolumn{2}{|c|}{$1.2620 \cdot 10^{6}$} \\
\hline Intermediate Members & \multicolumn{2}{|c|}{$7.6937 \cdot 10^{5}$} \\
\hline A and B Members & $\begin{array}{l}\text { Max Diameter } \\
2.8708 \cdot 10^{5}\end{array}$ & $\begin{array}{l}\text { Min Diameter } \\
5.2931 \cdot 10^{4}\end{array}$ \\
\hline Joints & $\begin{array}{c}\text { Torsional stiffness on } X \text { axis, } \\
\mathrm{N} \cdot \mathrm{m} / \mathrm{rad}\end{array}$ & $\begin{array}{c}\text { Torsional stiffness on } Y, Z \text { axes, } \\
\mathrm{N} \cdot \mathrm{m} / \mathrm{rad}\end{array}$ \\
\hline Root Member and Hub Joints & $4.4 \cdot 10^{5}$ & $7.5 \cdot 10^{5}$ \\
\hline Root and Intermediate Member Joints & $2.0 \cdot 10^{5}$ & $1.00 \cdot 10^{6}$ \\
\hline Intermediate and $\mathrm{A}(\mathrm{B})$ member Joints & $6.67 \cdot 10^{4}$ & $1.33 \cdot 10^{5}$ \\
\hline
\end{tabular}

Table 2. Properties of cord materials.

\begin{tabular}{|c|c|c|}
\hline Cords & Module of elasticity, Pa & Density $\mathbf{~ g g} / \mathbf{m}^{\mathbf{3}}$ \\
\hline Peripheral, Radial Cords & $9.83 \cdot 10^{9}$ & 2450 \\
\hline Inner Cords & $3.27 \cdot 10^{10}$ & 2339 \\
\hline Cords Joining of A and B Members Ends & $9.83 \cdot 10^{9}$ & 8000 \\
\hline Reflective Mesh & $1.3 \cdot 10^{6}$ & $0.02 \mathrm{~kg} / \mathrm{m}^{2}$ \\
\hline
\end{tabular}

\section{Numerical results for natural frequencies and mode shapes}

Natural frequencies and, respectively, mode shapes are calculated using the finite element method. Boundary conditions are: pretentions in inner cords $-10 \mathrm{~N}$, pretentions in peripheral cords $-250 \mathrm{~N}$, pretentions in tension ties $-1 \mathrm{~N}$, pretentions in reflective mesh $-2 \mathrm{~N} / \mathrm{m}$, pretentions in cords which connect ends of A and B members $-90 \mathrm{~N}$, pretentions in others cords $-100 \mathrm{~N}$. Reflector is fixed at central hub. Figures 4-5 show mode shapes and, respectively, natural frequencies. Arrows on figures 9-10 show oscillation directions. 


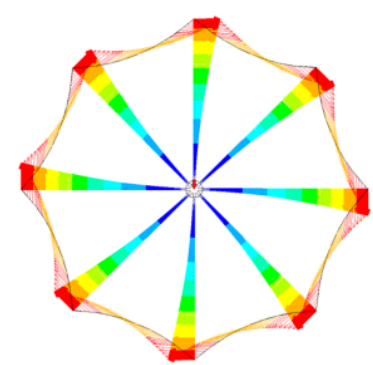

a)

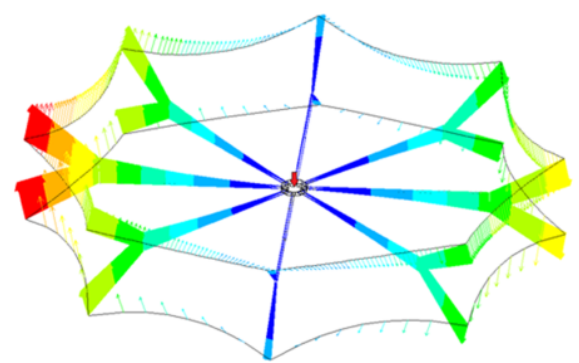

b)

Figure 4. First and second mode shapes with frequency of: a) $0.525 \mathrm{~Hz}$; b) $0.546 \mathrm{~Hz}$.

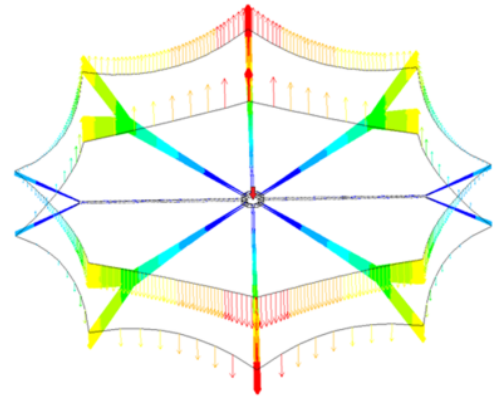

a)

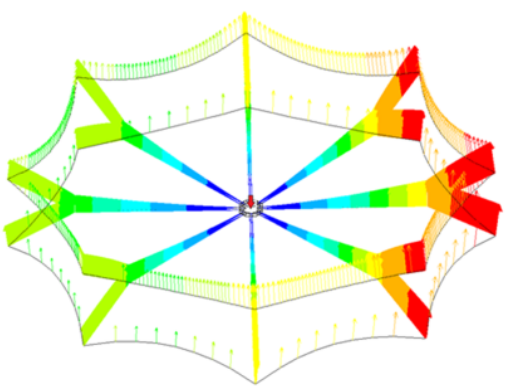

b)

Figure 5. Third and fourth mode shapes with frequency of: a) $0.577 \mathrm{~Hz}$; b) $0.647 \mathrm{~Hz}$.

\section{Conclusion}

The present work describes the stiffness estimation based on natural frequencies for new large sized umbrella type space reflector. A link between natural frequencies and static deflection is identified. A finite element model is designed for described reflector. As a result of numerical analysis mode shapes and, respectively, frequencies are presented.

\section{Acknowledgement}

This work has been financially supported by The Ministry of Education and Science of The Russian Federation. Unique identifier RFMEFI57814X0073.

\section{References}

1. S. Morterolle, B. Maurin, J. Quirant, C. Dupuy, AA 76 (1), 154 (2012)

2. A. G. Tibert, Thesis work (Department of Mechanics, Royal Institute of Technology, Sweden, 2002)

3. S. Timoshenko in collaboration with D. H. Young, Vibrations Problems in Engeneering, Third edition (D. Van Nostrand Company, Inc, Toronto- New-York - London, 1955)

4. S. Ponomarev, A. Zhukov, A. Belkov, V. Ponomarev, S. Belov, M. Pavlov, IOP Conf. Series: M SE 71012070 doi:10.1088/1757-899X/71/1/012070 (2015)

5. K.-J. Bathe, Finite element procedures (Prentice-Hall. Englewood Cliffs, 1996) 